\title{
Implementation of the supercapacitor-assisted surge absorber (SCASA) technique in a practical surge protector
}

\author{
Jayathu Fernando, Nihal Kularatna, Howell Round and Sadhana Talele \\ School of Engineering \\ University of Waikato \\ Hamilton, New Zealand. \\ lhdkf1@,waikato.ac.nz, nihalkul@waikato.ac.nz, h.round@waikato.ac.nz, sadhana@waikato.ac.nz
}

\begin{abstract}
Their combination of large continuous energy ratings and very large time constants allows supercapacitors to be used in surge protection circuits. This fact, supported by recent research publications and laboratory tests, has assisted the authors to propose a new surge protection circuit topology known as the supercapacitor-assisted surge absorber (SCASA). This technique utilizes a multi-winding transformer, common surge protector devices such as metal oxide varistors (MOV) and/or semiconductor types combined with a supercapacitor sub-circuit to absorb part of the surge energy usually expected to dissipate within the MOV or the semiconductor. The paper presents design details and test results for a differential mode surge protector based on the SCASA technique where the test device was subjected to lightning-type surges defined in international standards for Class-A and Class $B$ type protectors. The performance of a prototype based on Class-B waveforms of up to $6.6 \mathrm{kV}$ surges generated from a lightning surge simulator are discussed in the paper. Its performance is compared with two commercially available surge protectors.
\end{abstract}

Keywords-surge protector, supercapacitor, metal oxide varistor, semiconductor type SPD

\section{INTRODUCTION}

With the International Technology Roadmap for Semiconductors predicting sub- $25 \mathrm{~nm}$ feature-size VLSIs, powered by DC power supplies of less than $1 \mathrm{~V}$, protection against transients has become mandatory for modern electronic systems [1]. Surge protection circuits are usually designed using non-linear devices such as metal oxide varistors (MOV) and semiconductor devices. These devices are rated for shortterm energy absorption, based on transient waveforms defined by standards such as IEEE C62.41 [2]. However, when these surge protector units are subjected to repeated surges, MOVs and semiconductor-type devices used in the circuit could gradually heat up and fail eventually. Also, if the unit is subjected to statistically-higher peak value surges repeatedly, the individual components within the protector can fail and the unit could become unable to absorb the surge and protect the connected critical load.

For the above reasons, a reliable surge protector is usually over-designed and consists of cascaded multiple filter stages

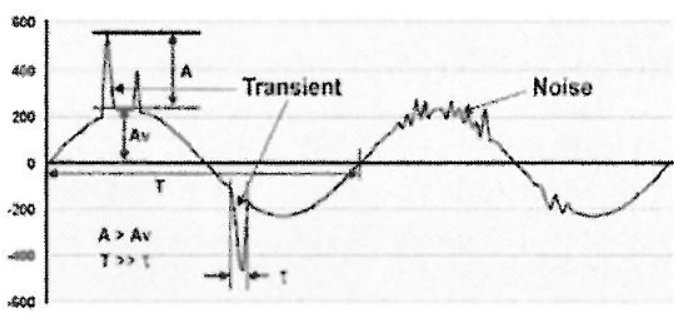

(a)

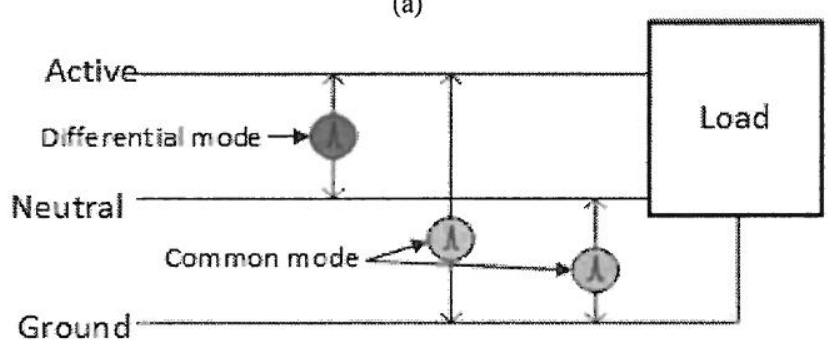

(b)

(c)

Fig. 1. Transients superimposed on $\mathrm{AC}$ mains, different modes of surges and a typical surge protection circuit (a) short duration transients superimposed on an $\mathrm{AC}$ waveform (b) differential and common mode surges, (c) a typical commercial surge protector circuit.

and over-rated MOVs and semiconductor-type devices. A good surge protection device should be designed to absorb both common mode and differential mode surges as shown in Fig. 1(b). However, the design principles to be applied for these two types of surges are the same. 
Section II of this paper provides an overview of supercapacitor (SC) applications and their surge absorption capability. How the supercapacitor-assisted surge absorber (SCASA) circuit is designed is discussed in Section III.

\section{SUPERCAPACITORS AND THEIR SURGE ABSORPTION CAPABILITY}

\section{A. Traditional uses of supercapacitors}

During the past decade, supercapacitor technology has matured quite rapidly with low-voltage DC-rated devices having been introduced by many companies worldwide. A few examples of such manufacturers are Maxwell [3] (USA), CapXX [4] (Australia) and Nesscap [5] (Korea). Common applications of SCs are short-term energy storage [6-8], batterysupercapacitor hybrid combinations [9-11], short-term backup for DC power sources and supplies [12-14] and catering for short duration power peaks in portable products such as cellular phone transmit pulses and high-brightness flashes. The thin profile Cap-XX supercapacitor family is suitable for consumer applications such as cellular phones and cameras [15-16].

\section{B. Supercapacitors' ability to absorb surge}

As per the details in $[17,18]$, the authors of this paper have subjected different commercial versions of supercapacitor families to IEEE C62.41 standard [2] surges repeatedly and found that almost all commercial SCs families can withstand repeated surges up to $6.6 \mathrm{kV}$ (which is the limit for surge generator used by the authors). For example, a thin-profile Cap-XX 0.18 F, $2.3 \mathrm{~V}$ device was able to withstand over 150 repeated surges of $6.6 \mathrm{kV}$. Maxwell $230 \mathrm{~F}, 2.5 \mathrm{~V}$ and NessCap $90 \mathrm{~F}, 2.7 \mathrm{~V}$ devices did not fail even after 700 repeated $6.6 \mathrm{kV}$ surges. More details on this is available in Ref. [18]

\section{THE SCASA TECHNIQUE}

Based on above work, the authors have developed a unique surge absorber topology named the supercapacitor-assisted surge absorber (SCASA), where a SC's continuous surge energy absorption capability given by $1 / 2 C V^{2}$ could be effectively used with several other components such as MOVs, LC filters and multi-winding magnetic components. This magnetic part works as a transformer when a surge travels through the power line and fires a nonlinear device (NLD) such as a MOV or a semiconductor device such as bidirectional break-over device (BBD).

As Fig. 2(a) shows, due to the transformer's action, when the MOV fires a transient voltage is induced in the secondary winding which opposes the incoming high-voltage surge. This, in effect, reduces the voltage applied to the critical load. As shown in Fig 2(b), when the MOV fires an induced transient voltage appears across primary coil $\left(\mathrm{L}_{\mathrm{p}}\right)$ and, in turn, a secondary voltage across $\left(\mathrm{L}_{\mathrm{s}}\right)$, based on transformer theory. More details and formulae related to this are in [19]. As Fig. 2(b) shows, due to the induced voltage on the secondary winding, the load $\left(\mathrm{V}_{\text {Load }}\right)$ sees a waveform with a negative dip. The result is a cancelling pair of transient voltages across the ends of two coils, where the SC sub-circuit is placed as per Fig. 2(c).The different sub circuit configurations are shown as

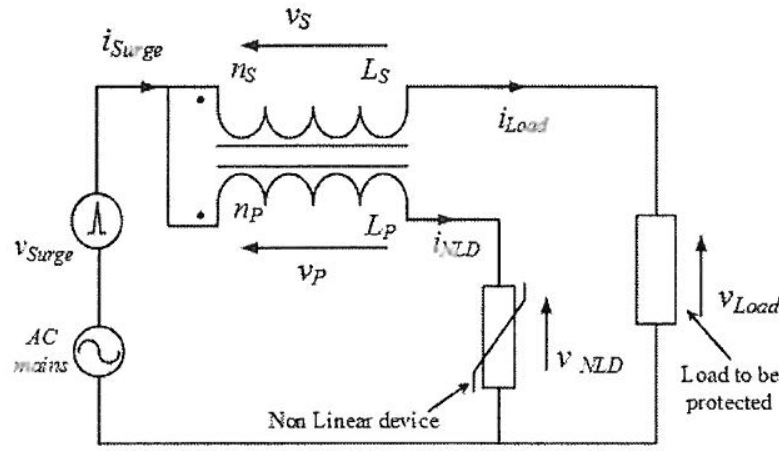

(a)

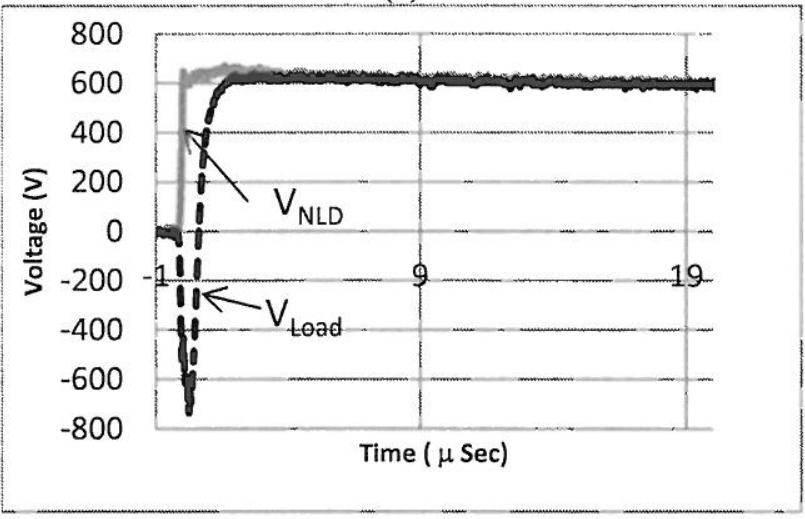

(b)

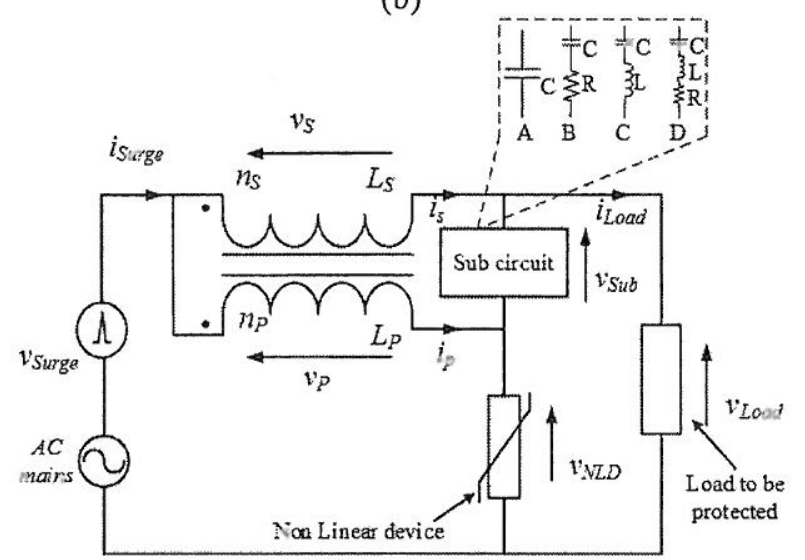

(c)

Fig.2. SCASA concept, waveforms and implementation (a) Operation principle.(b) Oscillograph indicating voltage variation at the load and nonlinear device when $6 \mathrm{kV}$ surge applied to the circuit in Fig. 3(a). (c) Overall implementation with supercapacitor sub circuit

A,B,C,D in Fig. 2(c). The resistor, capacitor series sub circuit (type B) is found more effective and the Fig.3 shows the effect of the capacitor size on the voltage across the sub circuit $\left(V_{S u b}\right)$. It is clear that smaller capacitance $(50 \mathrm{nF})$ creates oscillations across the sub circuit when the surge current $\left(I_{\text {surge }}\right)$ flows in and hence creates oscillating voltage across the load as well. But the high capacitance (5F supercapacitor) creates a negative voltage across the sub circuit with the injection of Isurge. The impact of this is to show a much lower transient voltage across the critical 


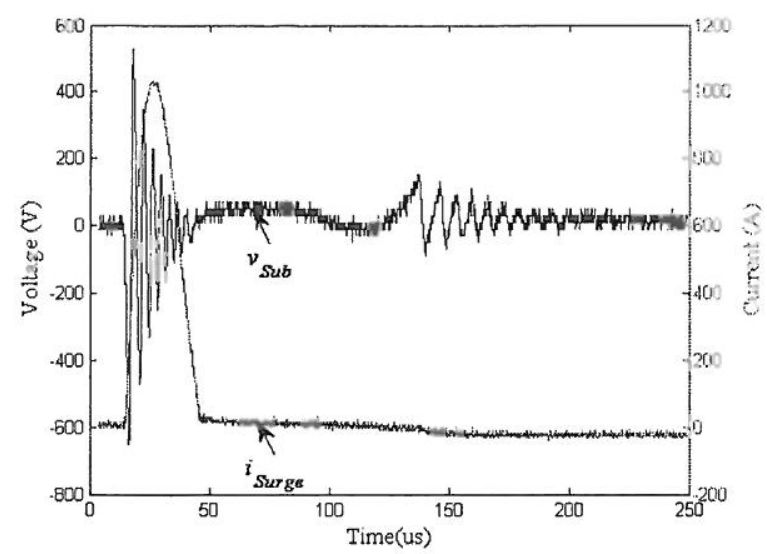

(a)

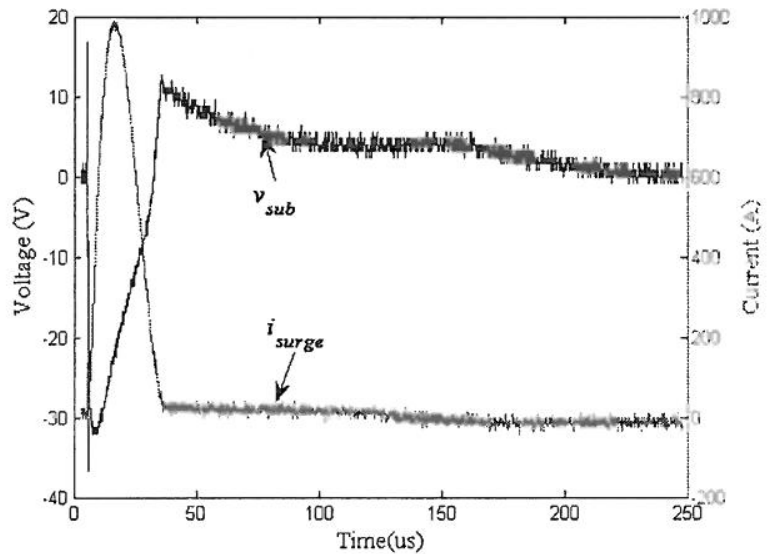

(b)

Fig. 3. Voltage waveforms generated across the sub circuit for $3 \mathrm{kV}$ surge input (a) $50 \mathrm{nF}$ capacitor and $1 \Omega$ sub circuit (b) $5 \mathrm{~F}$ capacitor and $1 \Omega$ sub circuit

load ( $\left.\mathrm{V}_{\text {Load }}\right)$. More details are found in [19]. A useful feature of this SCASA topology is that the SC sub-circuit is maintained at near-zero AC voltage. At normal operation the NLD shows very high resistance and hence very small leakage current flows through it. The voltage drop across the secondary coil is also very small due to low inductance and low resistance of the coil. Hence the voltages across varitor and load are almost equal. Due to this the sub circuit maintains near -zero voltage. This helps to avoid the exposure of low DC voltage rated SCs to AC voltage differences in normal AC power operation.

\section{IMPLEMENTATION}

Fig. 4(a) shows a practical implementation of the SCASA concept in a differential-mode-only protector circuit. The SC sub-circuit is formed by a $1 \Omega$ resistor and a $5 \mathrm{~F}, 2.7 \mathrm{~V} \mathrm{SC}$ in series. The first MOV, $\operatorname{Var}_{1}$, is a $413 \mathrm{KD} 14$ with a maximum clamping voltage $710 \mathrm{~V}$ together with SC sub-circuit-created input/output waveforms as per Fig 4(b) and 4(c). The yellow trace $\left(V_{V a r l}\right)$ shows the voltage across the varistor, and the blue line shows the voltage across the load $\left(V_{\text {Load }}\right)$. The violet and the green lines are the surge voltage $\left(V_{\text {Surge }}\right)$ and the surge

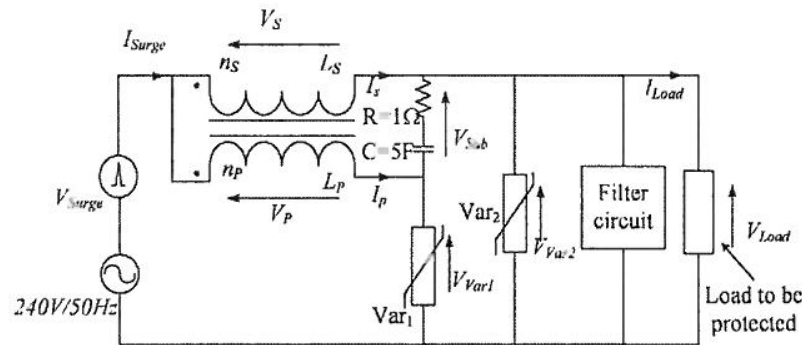

(a)

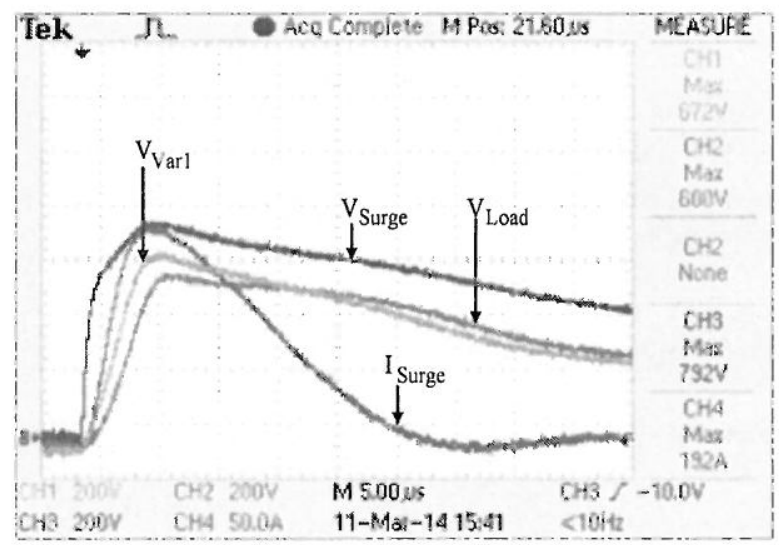

(b)

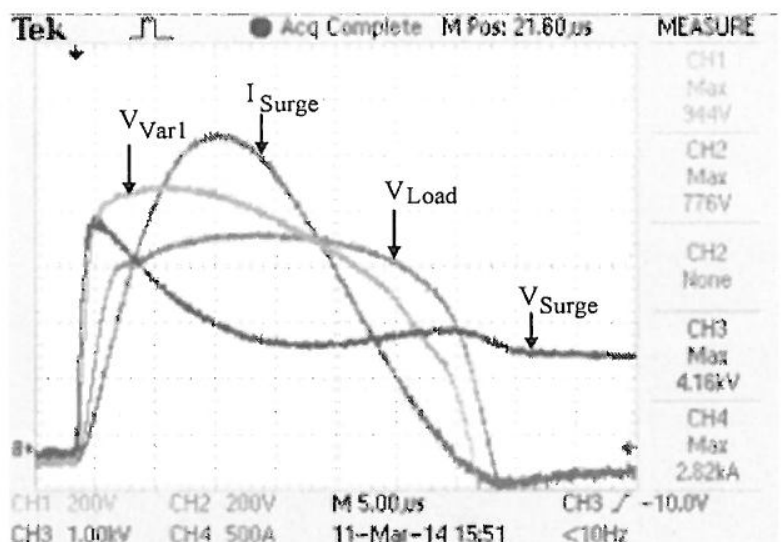

(c)

Figure 4: SCASA implementation (a) Circuit with final components (b) Oscillograph for $1 \mathrm{kV}$ surge input (c) Oscillograph for $6.6 \mathrm{kV}$ surge input.

current $\left(I_{\text {Surge }}\right)$ fed to the circuit in Fig 4(a) which were generated by a NoiseKen LSS 6230 surge simulator.

Fig. 5 shows how the performance of SCASA implementation compares with two other commercially-available products sold in New Zealand and Australia. Two different secondary MOV options (at $\operatorname{Var}_{2}$ ) were tested and the respective graphs show that in both cases the performance of SCASA is superior to the two commercial versions. Table 1 compares components used in the three cases, showing that the SCASA technique is more effective in reducing the component count. 


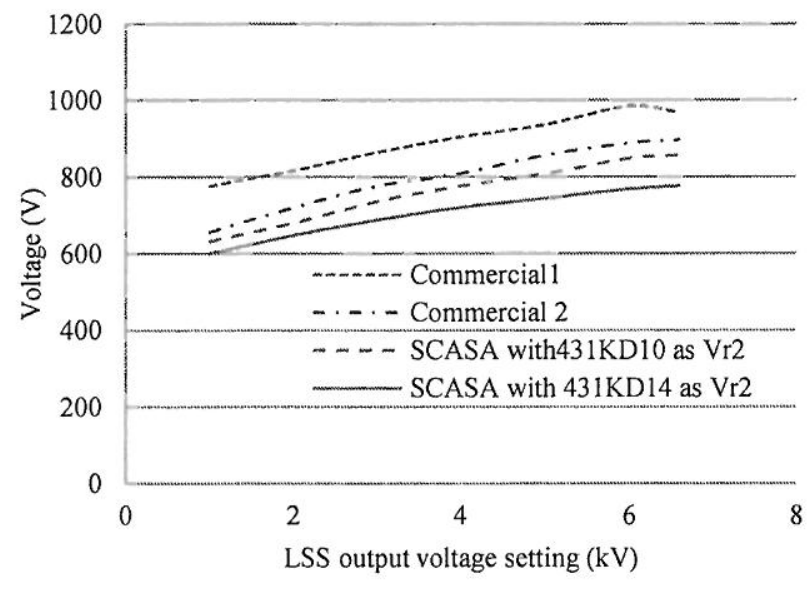

Figure 5: Comparison of SCASA circuit implementation with two other commercial surge protectors

TABLE 1. COMPONENT COUNT COMPARISON IN SURGE PROTECTORS

\begin{tabular}{|c|c|c|c|}
\hline \multirow[b]{2}{*}{$\begin{array}{c}\text { Component } \\
\text { type }\end{array}$} & \multicolumn{3}{|c|}{ No. of components* } \\
\hline & $\begin{array}{c}\text { High- } \\
\text { performance } \\
\text { product }\end{array}$ & $\begin{array}{l}\text { Low-cost } \\
\text { product }\end{array}$ & SCASA \\
\hline MOVs & 4 & 1 & 2 \\
\hline SCs & 0 & 0 & 1 \\
\hline Inductors & 2 & 0 & 1 \\
\hline Capacitors & 5 & 1 & 4 \\
\hline
\end{tabular}

TABLE 2. TEST RESULTS OF VARISTOR FOR 6.6KV REPEATED SURGES

\begin{tabular}{|c|c|c|c|}
\hline \multirow{2}{*}{ Varistor } & \multirow{2}{*}{$\begin{array}{c}\text { Rated } \\
\text { Energy } \\
(\mathbf{J})\end{array}$} & \multicolumn{2}{|c|}{$\begin{array}{c}\text { Number of surges cause } \\
\text { the device to fail }\end{array}$} \\
\cline { 3 - 4 } & $\mathbf{1 0 / 1 0 0 0} \boldsymbol{\mu s}$ & Sample 1 & Sample 2 \\
\hline $431 \mathrm{KD} 10$ & 66 & 7 & 10 \\
\hline $431 \mathrm{KD} 14$ & 132 & 34 & 27 \\
\hline
\end{tabular}

\section{TEST RESULTS FOR REPEATED SURGES}

Using the lightning surge simulator, the individual components used in SCASA implementation were subjected to repeated Class-B category surges (with a 30-second delay between the surges) until they finally failed. Then the SCASA overall circuit was subjected Class-B surges with same peak amplitudes repeatedly. Test results for varistors are shown in Table 2. The SCASA circuit could withstand more than 100 repeated surges, while its individual MOVs tend to fail much earlier when individually subjected to surges of same amplitude as in Table 2.

Since the resistor used, $R_{1}$, was not able to withstand surges up to $6.6 \mathrm{kV}$, it was subjected to gradually increasing surges and the device failed around a peak value of approximately $5 \mathrm{kV}$.
The test indicated clearly this SCASA circuit could withstand higher number of repeated surges, than each component could withstand.

\section{CONCLUSION}

As the test results clearly indicate, the SCASA is a new (patented [20]) technique where performance per component count is lower than the tested commercial products. This shows that that the new SCASA topology could be used as a base technique to develop full-scale common and differential mode surge capable, fully versatile, commercial surge protectors with better performance than traditional surge protectors with higher component counts. The research team is currently developing advanced models to analyze the overall circuit, in order to predict its theoretical performance in detail.

\section{REFERENCES}

[1] The International Technology Roadmap for Semiconductors (ITRS): executive summary, 2011, p. 98.

[2] IEEE Recommended Practice on Characterization of Surges in LowVoltage (1000 V and Less) AC Power Circuits, 2002, IEEE Standard C62.41.2.

[3] www.maxwell.com/ultracapacitors

[4] www.cap-xx.com

[5] www.nesscap.com

[6] W. Maranda, M. Piotrowicz, "Application of photovoltaics for daytime indoor lighting," in IEEE 2011 Mixed Design of Integrated Circuits and Systems (MIXDES) conference, 2011, pp 529-532.

[7] A.B. da Cunha, D.C. da Silva, "Energy-efficient characterization of solar panel-supercapacitors systems for energy-harvesting aware wireless sensor nodes", in IEEE 20th International Symposium on Personal, Indoor and Mobile Radio Communications, 2009, pp. 2275.

[8] Zhongdong Yin, Minxiao Han, Yunlong du, Zheran Zhang, "A practical approach for ride through of super capacitor energy storage based ASD ystem," in IEEE 2005/2006 Transmission and Distribution Conference and Exhibition, 2006, pp. 744 - 746.

[9] Yu Zhang , and Zhenhua Jiang "Dynamic power sharing strategy for active hybrid energy storage systems," in IEEE 2009 Vehicle Power and Propulsion Conference, 2009, pp.. $558-563$.

[10] A.M. Gee, and R.W.Dunn, "Novel battery / supercapacitor hybrid energy storage control strategy for battery life extension in isolated wind energy conversion systems," in IEEE 2010 Universities Power Engineering Conference (UPEC), 2010, pp. 1 - 6.

[11] K.W. Wee, S.S. Choi, D.M. Vilathgamuwa, "Design of a renewable hybrid energy storage power scheme for short-term power dispatch" in IEEE 2011 Electric Utility Deregulation and Restructuring and Power Technologies (DRPT) conference, 2011, pp. 1511-1516.

[12] E. Christopher, M. Sumner,A. Szabo, E. Introwicz, "Power boost unit for automotive electric power steering systems," in IET 2010 Power Electronics, Machines and Drives (PEMD 2010) conference, 2010, pp. 1 $-5$

[13] E. Ribeiro, A. J. Marques Cardoso, C. Boccaletti, "Fuel cellsupercapacitor system for telecommunications," in IET 2010 Power Electronics, Machines and Drives (PEMD 2010) conference, 2010, pp. 1 -6 .

[14] R.F. Coelho, L. Schimtz, D.C. Martins, "Grid-connected PV-wind-fuel cell hybrid system employing a supercapacitor bank as storage device to 
supply a critical DC load", in IEEE 2011 Telecommunications Energy Conference (INTELEC), 2011, pp $1-10$.

[15] S. Harris "Supercapacitors brighten prospects for power LED flash in camera phones", LEDs Magazine, UK, February 2007.

[16] J. Monteiro, N. Garrido, R. Fonseca, "Efficient supercapacitor energy usage in mobile phones," in IEEE Consumer Electronics - Berlin (ICCEBerlin), 2011, pp.318-321.

[17] N. Kularatna, J. Fernando, A. Pandey, "Surge endurance capability testing of supercapacitor families", Proc. 36th Annual IECON 2010 conference of IEEE Industrial Electronics Society, 2010 , pp. 1858 1863.

[18] N. Kularatna, J. Fernando, S. James, A. Pandey, "Surge capability testing of supercapacitor families using a lightning surge simulator", IEEE transactions on Industrial Electronics, 2011,58, 10 ,pp.. $4942-4949$.

[19] J. Fernando, N. Kularatna, "A supercapacitor based enhancement technique for stand-alone surge protection circuits", Proceedings of IEEE-ISIE 2013, Taipei, Taiwan, May 2013, pp. 1-7.

[20] Nihal Kularatna and Lewis J. Fernando, "Power and Telecommunication Surge Protection Apparatus", New Zealand patent number 604332, 21st March 2014 